\title{
Correlation of cholinergic abnormalities with senile plaques and mental test scores in senile dementia
}

\author{
ELAINE K PERRY, BERNARD E TOMLINSON, GARRY BLESSED, KLAUS BERGMANN, \\ PETER H GIBSON, ROBERT H PERRY
}

relation between changes in the cholinergic system and a major aspect of the Alzheimer disease process.

\section{Summary and conclusions}

Necropsy brain tissue from normal (control) patients and patients with depression and dementia was examined for activities of various cholinergic components, and these related to the degree of senile plaque formation and extent of intellectual impairment. Choline acetyltransferase and acetylcholinesterase activities decreased significantly as the mean plaque count rose, and in depressed and demented subjects the reduction in choline acetyltransferase activity correlated with the extent of intellectual impairment as measured by a memory information test; muscarinic cholinergic receptor binding activity remained unchanged with increasing senile plaque formation but butyrylcholinesterase activity increased.

The results suggest a close relation between changes in the cholinergic system and Alzheimer's dementia, but the precise role of the system in this disease remains to be elucidated.

\section{Introduction}

The clinical and neuropathological features of senile dementia of Alzheimer type (SDAT) are well established but neurochemical observations are few. Consistent reports of a cholinergic abnormality have been published. ${ }^{1-3}$ Enzymes that synthetise and degrade acetylcholine-namely, choline acetyltransferase $(\mathrm{CAT})^{1-3}$ and acetylcholinesterase $(\mathrm{ACE})^{1+}$-are significantly decreased in SDAT compared with normal brain tissue. The reduction in CAT activity in certain brain regions tends to parallel the distribution of histopathological abnormalities, which may indicate an association with the disease itself rather than with non-specific factors such as cerebral malfunction, drug treatment, and terminal disease."

We have investigated the quantitative relation between the numbers of senile plaques (one of the most prominent pathological changes in SDAT) and cholinergic biochemical activities. Since senile plaques occur in normal old age and their numbers correlate significantly with the degree of cognitive impairment, ${ }^{6}$ measurement of cholinergic activities in brain samples with varying degrees of senile change may elucidate further the

\footnotetext{
Newcastle Area Health Authority (Teaching), Newcastle General Hospital, Newcastle upon Tyne NE4 6BE

ELAINE K PERRY, BSC, PHD, research biochemist

BERNARD E TOMLINSON, MD, FRCPATH, honorary professor of pathology and consultant pathologist

GARRY BLESSED, FRCPED, FRCPSYCH, clinical lecturer in psychiatry and consultant psychiatrist (psychogeriatrics)

PETER H GIBSON, BSC, PHD, research associate

ROBERT H PERRY, MRCP, MRCPATH, senior registrar in neuropathology

Bethlem Royal and Maudsley Hospitals, London SE5 8AZ

KLAUS BERGMANN, MD, FRCPSYCH, consultant psychiatrist
}

\section{Materials and methods}

Clinical-All subjects examined were hospital patients aged 61-92 years from an acute medical unit or a psychogeriatric department; 13 were normal (these served as controls), 10 depressive, and 28 demented. The demented and depressed patients were assessed psychiatrically, and in most a mental test score (memory, information, and concentration), which correlates with neuropathological abnormalities, ${ }^{6}$ was determined.

Biochemical-Tissue samples were taken at necropsy from the four cortical lobes (Brodmann areas 10, 21, 40, and 19) and stored in liquid nitrogen. Intervals between death and cadaver refrigeration ranged from one to seven hours, between death and tissue storage from five to 69 hours, and between storage and biochemical assay from three to 18 months. Protein concentrations and CAT, ACE, butyrylcholinesterase (BCE), muscarinic cholinergic receptor binding (MCRB), and glutamate decarboxylase (GAD) activities were measured in tissue homogenates $\left(0.32 \mathrm{M}\right.$ sucrose, $1^{\prime \prime}$. Triton X-100 being added for the enzyme assays) by standard methods. ${ }^{4}$ "Activities were expressed per mg protein and are given as the average value for the four cortical areas to correspond with the mean plaque count (see below).

Neuropathological-After removal of the tissue samples the intact brain was fixed in neutral formalin and examined by standard macroneuropathological and microneuropathological techniques. ${ }^{7} 8$ In addition to extensive general histological examination estimates were made of the three principal histological changes (referred to here as Alzheimer-type) found in SDAT: senile plaques were counted in standard areas of neocortex and a mean count derived; the numbers of cells affected by granulovacuolar degeneration in the hippocampus were defined; and the severity and distribution of Alzheimer's neurofibrillar degeneration in the neocortex and hippocampus were estimated on a five-point scale. Additionally multiple coronal slices were examined to determine the amount and distribution of cerebral softening.

\section{CLASSIFICATION OF CASES}

From the clinical, psychiatric, and neuropathological assessments patients were arranged in the following five groups.

(1) Normal-Normal patients were those dying from physical illnesses in acute general wards who had no known neurological or psychiatric disorders and whose mental ability and capacity for selfcare before admission were not in doubt. Histological examination showed no evidence of any specific neuropathological abnormality and either absence or only a minimal degree of Alzheimer-type change or cerebral softening, such as occurs in many intellectually wellpreserved elderly people. ${ }^{i}$

(2) Depression-Patients in this group had chronic unipolar depressive illness or various forms of reactive depression but were substantially normal intellectually. Neuropatholo ical findings were as in group 1.

(3) Multi-infarct dementia-These patients had clinical dementia in the presence of strokes, hypertension, or symptomatic epilepsy and a stepwise progression of symptoms. The brains showed substantial amounts of infarcted tissue without appreciable Alzheimer-type change.

(4) SDAT-In these patients dementia consisted of global impairment of higher cortical function with an insidious and progressive smooth downhill course. Histologically the brains showed widespread senile plaques, large numbers of neurofibrillar tangles throughout the 
neocortex, and severe granulovacuolar degeneration but minimal or no ischaemic damage.

(5) Dementia of "mixed" pathology-These patients were clinically demented with neuropathological features as in groups 3 and 4.

\section{Results}

Table I gives the mean cortical CAT and GAD activities in groups 1-5. Activity of the cholinergic enzyme CAT was significantly decreased only in those cases with Alzheimer-type pathology (groups 4 and 5), whereas activity of the $\gamma$-aminobutyric acid system enzyme GAD was significantly reduced in all abnormal groups. There were no significant differences between the groups in mean age or mean delay before necropsy (table I).

Further evidence of a specific involvement of the cholinergic system in Alzheimer-type pathology was provided by analysing the relation between enzyme activities and increasing senile plaque numbers. Figure 1 gives the individual mean CAT activities in the 51 cases and (inset) the mean CAT and GAD activities in cases grouped according to mean plaque count. CAT activities were clearly correlated with

TABLE I-Mean cortical choline acetyltransferase (CAT) and glutamate decarboxylase (GAD) activities (expressed as the mean of the four cortical lobes) mean age, and mean delay before necropsy in the five groups. All values $\pm S E$

\begin{tabular}{|c|c|c|c|c|c|}
\hline Group & $\begin{array}{c}\text { No of } \\
\text { patients }\end{array}$ & $\underset{\substack{\text { protein) } \\
\text { CAT }}}{\text { mol } / \mathrm{h} / \mathrm{mg}}$ & $\underset{\substack{\text { protein) } \\
\text { GAD }}}{\text { pal } / \mathrm{mg}}$ & $\underset{\text { (years) }}{\text { Age }}$ & $\begin{array}{c}\text { Necropsy } \\
\text { delay } \\
\text { (hours) }\end{array}$ \\
\hline $\begin{array}{l}1 \text { (normal) } \\
2 \text { (depression) } \\
3 \text { (multi-infarct }\end{array}$ & $\begin{array}{l}13 \\
10\end{array}$ & $\begin{array}{l}3.55 \pm 0.21 \\
2.95 \pm 0.29\end{array}$ & $\begin{array}{l}48 \cdot 5 \pm 7 \cdot 3 \\
23 \cdot 5^{*} \pm 5 \cdot 5\end{array}$ & $\begin{array}{l}76 \pm 3 \\
73 \pm 2\end{array}$ & $\begin{array}{l}26 \pm 6 \\
34 \pm 3\end{array}$ \\
\hline $\begin{array}{c}\text { dementia) } \\
5 \text { ( } \begin{array}{c}\text { (mixed-type } \\
\text { dementia) }\end{array}\end{array}$ & $\begin{array}{r}5 \\
18 \\
5\end{array}$ & $\begin{array}{r}3.82 \pm 0.36 \\
1 \cdot 40^{* * *}=0.13 \\
1.48^{* * *} \pm 0.22\end{array}$ & $\begin{array}{r}11 \cdot 1^{* * *} \pm 4 \cdot 9 \\
17 \cdot 6^{* *} \pm 5 \cdot 4 \\
10 \cdot 6^{* * *} \pm 4 \cdot 4\end{array}$ & $\begin{array}{l}78 \pm 3 \\
79 \pm 2 \\
82 \pm 4\end{array}$ & $\begin{array}{l}35 \pm 8 \\
27 \pm 5 \\
26 \pm 3\end{array}$ \\
\hline
\end{tabular}
Significance of difference from normal value (Student's $t$ test): ${ }^{*} \mathrm{P}<0.02$;
$* * \mathrm{P}<0.002 ; * * * \mathrm{P}<0.001$.

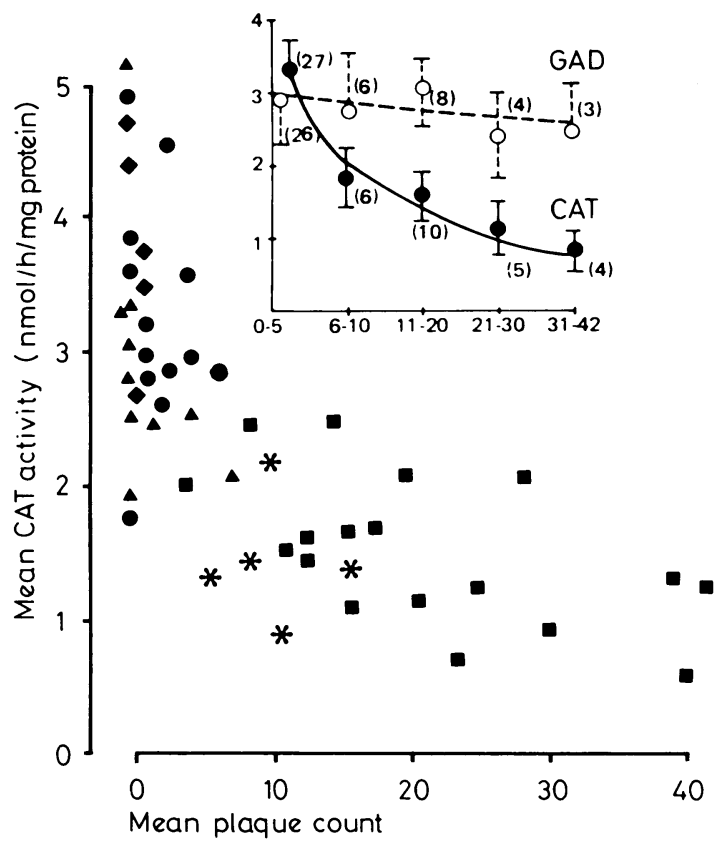

Relation between choline acetyltransferase (CAT) activity and senile plaque formation in cerebral cortex. Individual mean plaque counts plotted against mean cortical enzyme activities in 51 cases. $(\boldsymbol{\theta}=$ Normal. $\boldsymbol{\Delta}=$ Depression. = Multi-infarct dementia. $=$ SDAT. $*=$ Dementia of mixed pathology.) Inset shows mean CAT and glutamate decarboxylase (GAD) activities ( \pm SE) in cases arranged, irrespective of clinical and neuropathological grouping, according to mean plaque count. CAT expressed in $\mathrm{nmol} / \mathrm{h} /$ $\mathrm{mg}$ protein, and GAD in $\mathrm{nmol} \times 10 / \mathrm{h} / \mathrm{mg}$ protein (numbers of cases in parentheses).

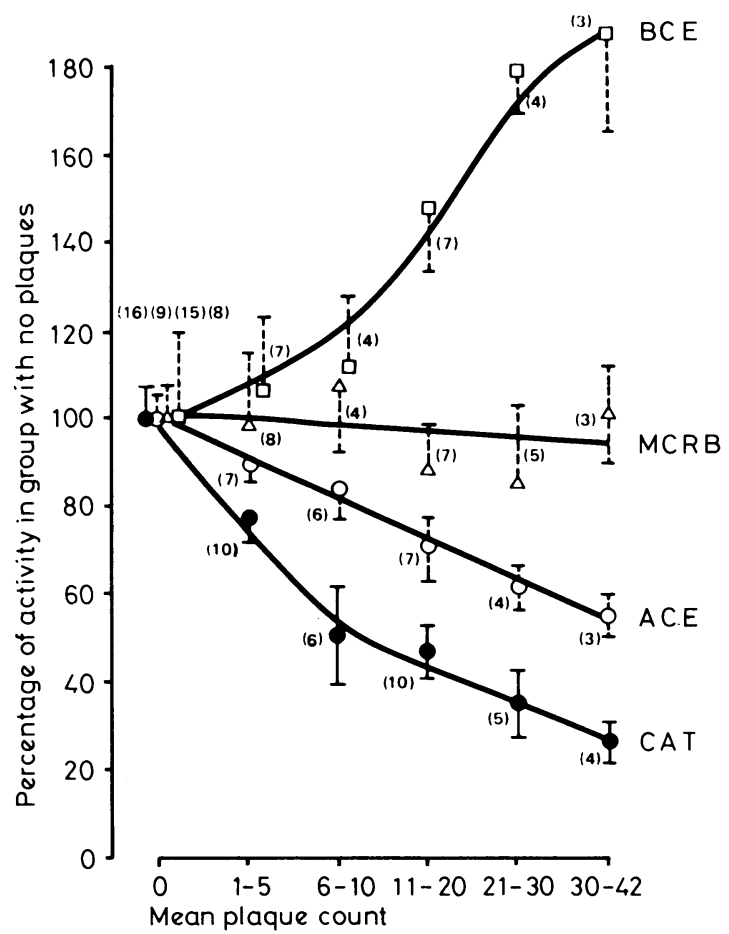

FIG 2-Relation between muscarinic cholinergic receptor binding (MCRB), acetylcholinesterase (ACE), butyrylcholinesterase (BCE), and choline acetyltransferase (CAT) activities and numbers of senile plaques in cerebral cortex. Cases from groups 1-5 arranged according to mean plaque count. Mean cortical activities of enzymes and receptor expressed as percentage of activity in cases with zero plaque count. Points are means $\pm S E$ (numbers of cases in parentheses).

BCE (33 cases): $r=0.38 ; P<0.05 . M C R B(42): r=0 \cdot 19$ $\mathrm{P}>0.05$. ACE (36): $\mathbf{r}=-0.49 ; \mathrm{P}>0.01$. CAT (51): $\mathrm{r}=-0.82 ; \mathrm{P}<0.001$.

increasing plaque formation $(\mathrm{r}=-0.82 ; \mathrm{P}<0.001)$ but GAD activities were not $(r=-0 \cdot 21)$. At lower plaque counts, corresponding to earlier stages of Alzheimer pathology (about 5-10 plaques per field), CAT activity was substantially reduced (to half the activity in the group with no plaques), whereas GAD activity was apparently unaltered.

Figure 2 gives changes in other components of the cholinergic system (ACE and MCRB) and BCE in relation to increasing plaque formation. MCRB was apparently unchanged, and although significant correlations were found between mean plaque count and the two cholinesterases, CAT activity still showed the greatest change at lower plaque counts.

Figure 3 shows the relation between the cholinergic and $\gamma$-aminobutyric acid system enzymes (CAT and GAD) and mental test scores in 23 depressed and demented subjects with no ischaemic brain damage (groups 2 and 4 ). There was clearly a significant correlation between the mental test score and CAT activity $(r=0.81 ; P<0.001)$ but not GAD activity $(\mathrm{r}=0 \cdot 16 ; \mathrm{P}>0.05)$.

\section{Discussion}

Our results suggest a close relation between plaque formation and CAT activity in the cerebral cortex and possibly a specific involvement of the cholinergic system in SDAT. The cholinergic $^{1-4}$ but not $\gamma$-aminobutyric $\operatorname{acid}^{5}{ }^{9}$ system defects, previously reported in SDAT were directly related to the severity of morphological abnormality as measured by the numbers of senile plaques and to the degree of intellectual impairment. Furthermore, our observation that in multi-infarct dementia cortical activities of CAT are apparently normal tend to exclude the possibility that decreased cortical CAT activity in SDAT may be due to non-specific factors such as institutionalisation, terminal illness, and drug treatment. 


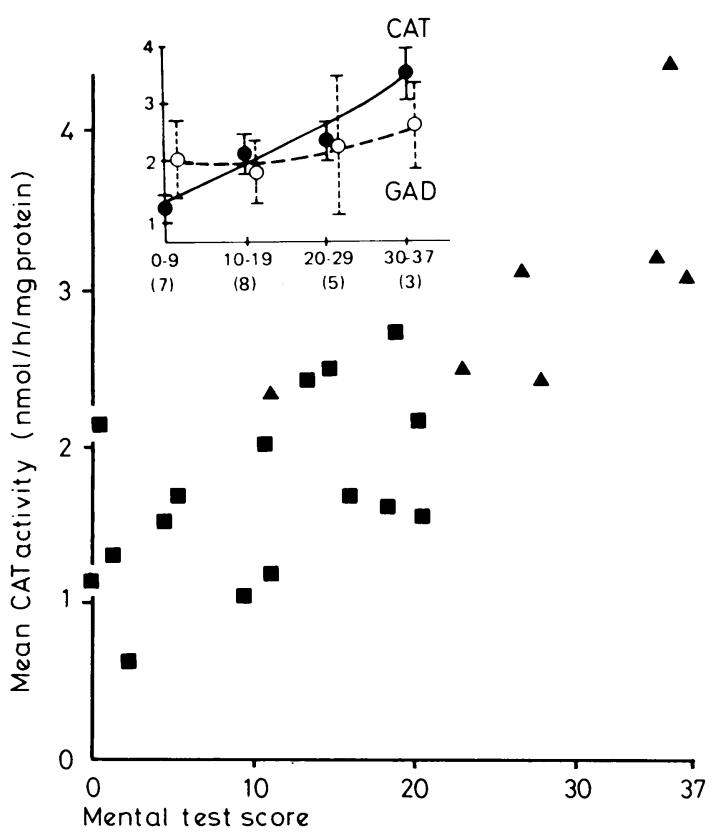

FIG 3-Relation between cortical choline acetyltransferase (CAT) activity and mental test score. Mean cortical enzyme activities in depressed $(\boldsymbol{\Delta})$ and demented $(\square)$ patients with no ischaemic brain damage (groups 2 and 4 ) plotted against mental test scores (optimum performance 37) obtained within six months of death. Inset shows CAT and glutamate decarboxylase (GAD) activities in cases grouped according to mental test score. CAT expressed in $\mathrm{nmol} / \mathrm{h} / \mathrm{mg}$ protein, and $\mathrm{GAD}$ in $\mathrm{nmol} \times 10 / \mathrm{h} / \mathrm{mg}$ protein (numbers of cases in parentheses).

TABLE II-Evidence suggesting cholinergic abnormality in SDAT

Evidence:

Observation
Neurochemical:

Decreased CAT in necropsy brain tissue $\mathrm{e}^{1-3}$

Decreased CAT in necropsy brain tissue 1 1-3
Decreased ACE in necropsy brain tissue

Psychopharmacological:

Anticholinergic drugs increase confusion in elderly patients ${ }^{10} 11$

Premedication with hyoscine induces amnesia ${ }^{12} 1$ Hyoscine administered experimentally induces learning deficits and senile
cognitive function ${ }^{1415}$

These observations are compatible with a "cholinergic hypothesis" of SDAT in which functional abnormalities are postulated to be associated with defective cholinergic neurotransmission. Table II summarises the biochemical and psychopharmacological evidence in favour of such a hypothesis. In addition to brain biochemical observations, the effects of certain drugs, clinically and experimentally, indicate a possible hypoactivity of cholinergic function in senile dementia and old age. Thus anticholinergic drugs may induce or increase confusion in elderly patients ${ }^{1011}$ and, clinically and experimentally, induce memory deficits and senile intellectual changes in normal adults. ${ }^{12-15}$ Furthermore, antipsychotic drugs (presumed to antagonise dopaminergic activity) reportedly ${ }^{16}$ have fewer extrapyramidal side effects (thought to reflect relative cholinergic hyperactivity) in demented than normal patients, which may indicate diminished cholinergic activity in the demented.

Loss of cortical CAT activity, compared with the other changes in SDAT reported here, may be an early abnormality. Since CAT is principally located in the nerve terminal, ${ }^{17}$ enzyme loss is compatible with the nerve terminal abnormalities associated with senile plaque formation. ${ }^{18}$ Diminished CAT activity could possibly account for the apparent lack of measurable clinical improvement in severely and moderately affected patients given oral choline. ${ }^{1920}$ Although choline enhances cholinergic transmission in normal animal brains, ${ }^{21}$ it remains to be established as effective in tissue with subnormal CAT activity. And, although the use of cholinergic drugs in diseases of the central nervous system is in its infancy, ${ }^{22}$ further approaches to countering a cholinergic defect in Alzheimer's dementia include the use of anticholinesterases, ${ }^{23}$ which might also be combined with CAT substrates such as choline. Furthermore, the possibility that acetylcholine release is defective in SDAT, as it is in the Eaton Lambert syndrome, might be tested by using guanidine, which is clinically useful in the latter condition. ${ }^{24}$

The role in SDAT of other neurotransmitter systems that may be amenable to neuropharmacological manipulation is not yet established. In contrast to the cholinergic system, preliminary results on necropsy brain ${ }^{1}$ suggest that the dopaminergic and noradrenergic systems may be spared, and our results do not specifically implicate the $\gamma$-aminobutyric acid system in Alzheimer-type pathology. Although our findings suggest a close relation between changes in the cholinergic system and SDAT the precise role of this neurotransmitter system in the disease process requires further investigation.

We are most grateful to the Newcastle Area Health Authority Research Committee and to the Medical Research Council for financial support; to Dr R Pennington for the use of biochemical facilities; to Mrs P Taylor for preparing the histological sections; and to the Wellcome Research Laboratories for provision of the acetylcholinesterase inhibitor, BW $284 \mathrm{C} 51$.

\section{References}

1 Davies, P, and Maloney, A F J, Lancet, 1976, 2, 1403.

${ }^{2}$ Perry, E K, et al, Lancet, 1977, 1, 189.

3 White, P, et al, Lancet, 1977, 1, 668.

${ }^{4}$ Perry, E K, et al, Neuropathology and Applied Neurobiology, 1978, 4, 273.

5 Perry, E K, et al, fournal of the Neurological Sciences, 1977, 34, 247.

${ }^{6}$ Blessed, G, Tomlinson, B E, and Roth, M, British fournal of Psychiatry, 1968, 114, 797 .

7 Tomlinson, B E, Blessed, G, and Roth, M, Fournal of the Neurological Sciences, 1970, 11, 205.

${ }^{8}$ Tomlinson, B E, Blessed, G, and Roth, M, fournal of the Neurological Sciences, 1968, 7, 331 .

9 Bowen, D M, et al, Lancet, 1974, 1, 1247.

10 Stephens, D A, British fournal of Psychiatry, 1967, 113, 213.

${ }^{11}$ Erikssen, J, Lancet, 1969, 1, 53.

12 Hardy, T K, and Wakely, D, Anaesthesia, 1962, 17, 331.

13 Pandit, S K, and Dundee, J W, Anaesthesia, 1970, 25, 493.

14 Crow, T J, and Grove-White, I G, British Fournal of Pharmacology, 1973, 49, 322 .

15 Drachman, D A, and Leavitt, J, Archives of Neurology, 1974, 30, 113.

${ }_{16}$ Silverman, G, British Medical fournal, 1977, 2, 318.

17 Fonnum, F, Biochemical fournal, 1967, 103, 262.

${ }^{18}$ Gonatas, N K, Anderson, A, and Evangelista, I, fournal of Neuropathology and Experimental Neurology, 1967, 26, 25.

19 Boyd, W D, et al, Lancet, 1977, 2, 711.

${ }^{20}$ Etienne, $\mathrm{P}$, et al, Lancet, 1978, 1, 508.

${ }^{21}$ Cohen, E L, and Wurtman, R J, Science, 1976, 191, 561.

${ }^{22}$ Karczmar, A G, in Biology in Cholinergic Function, p 395. New York, Raven Press, 1976.

${ }^{23}$ Comfort, A, Lancet, 1978, 1, 659.

24 Walton, J N, Brain's Diseases of the Nervous System, p 872. London, Oxford University Press, 1977.

(Accepted 29 September 1978)

ONE HUNDRED YEARS AGO On Saturday last, Miss Dodds, of the Edinburgh School of Cookery, delivered a demonstration lecture on Sick-room Cookery to over a hundred medical students, in the Extramural Class-room, Nicholson Square, Edinburgh. $\mathrm{Mr}$ Chiene presided, and in introducing the lecturer, impressed upon the students the importance of a knowledge of sick-room cookery to medical men. Miss Dodds then proceeded with her lecture, during which she demonstrated the process of making beef-tea, white wine whey, restorative jelly, and a number of other foods for invalids. The lecture was attentively and closely followed, and most of the students took notes. On the motion of $\mathrm{Mr}$ Chiene, a hearty vote of thanks was accorded to the lecturer, whose first lecture had, he said, been a gratifying and unqualified success. (British Medical fournal, 1878.) 